\title{
Life Cycle Inventory of Green Tea Production: Case of Gambung
}

\author{
Joko Waluyo ${ }^{1, *}$, Muthia Syafika Haq ${ }^{2}$, Ajeng Arum Sari ${ }^{1}$, Ary Mauliva Hada Putri ${ }^{1}$, \\ Muryanto $^{1}$, Adhi Irianto Mastur ${ }^{2}$, Teuku Beuna Bardant ${ }^{1}$, Sugeng Harianto ${ }^{2}$, Arief \\ Ameir Rahman Setiawan ${ }^{1}$, Anny Sulaswatty ${ }^{1}$ and Edi Iswanto Wiloso ${ }^{1}$ \\ ${ }^{1}$ Research Center for Chemistry, Indonesian Institute of Sciences (LIPI), Puspiptek, \\ Serpong, Indonesia \\ ${ }^{2}$ Research Institute for Tea and Cinchona (PPTK), Gambung, Indonesia
}

\begin{abstract}
Since long times ago, Indonesia has been known as one of foremost tea producers in the world. However, in recent years the total export contribution of Indonesian tea is declining. High competition and environmental sustainability issues is among the causing factors. Meanwhile, life cycle assessment has gained more attention to measure the potential impact of a product over its stages, from material extraction, production, distribution, consumption and product disposal. In this study, a life cycle inventory analysis has been performed to Indonesian green tea, using case of Gambung's green tea factory in West Java Province, Indonesia. Data collection and calculations intended to quantify inputs and outputs of green tea production. The analysis itself was done in the basis of literature study and field data collection. The result of such inventory analysis indicates that to produce 3.2 ton of bulk green tea, needs 15 ton of fresh tea leaf, 31 tubes LPG of $50 \mathrm{~kg}$ and 2.7 ton wood pellet are needed. This process also produces $54 \mathrm{~kg}$ waste of ash wood pellet, $130 \mathrm{~kg}$ crushed-burnt leaf, $65 \mathrm{~kg}$ residue, and 11.6 ton vapor released.
\end{abstract}

\section{Introduction}

Tea is being one of the most commonly consumed beverages in the world. It reaches $20.9 \%$ [1]. Indonesia has been historically known as one of tea producing countries in the world. According to FAO statistics 2014, Indonesia was the top seven global tea exporting country. Based on plantation statistics data from 2014, Indonesia has a total tea plantation area of 121,034 hectares [2]. Indonesia produced an average of 147,000 tonnes per year with an annual decline of $1.7 \%$. Increased environmental awareness impacts on trade so that information on environmental performance becomes a competitive value added product. At the global level, procedures for stating the potential environmental impact of a product are regulated in the standards of ISO 14021, 14024, and 14025.

\footnotetext{
*Corresponding author: joko.waluyo@lipi.go.id
} 
One method that is often used to calculate the potential environmental impact of a product is Life cycle assessment (LCA) (ISO 14040 and 14044: 2006) [3]. Besides being able to be used to state the environmental performance of a particular product, LCA is also used to compare one product with other products. Despite its importance to the economy, tea processing is predicted having contribution to negative environmental impacts, especially on the environment is related to energy and waste generation [4]. Tea factories emit gaseous as particulate pollutants from factory processes and exhaust fumes from boilers, standby generator sets. The environmental impacts of these pollutants. Exhaust fumes release carbon dioxide and nitrous oxides which are greenhouse gases that cause global warming, sulphur dioxide which is responsible for acid rain and particulate matter which affect human health. Tea factories also requires energy intensive. Life Cycle Inventory analysis (LCI) involves in the compilation and quantification of inputs and outputs for a given product system throughout its life cycle (ISO 14040 1998a). It utilizes process material and energy input-output data to characterize the use and emission of materials within and between processes.

Identifies and quantifies the environmental loads involved, e.g. the energy and raw materials consumed, the emissions and wastes generated (life cycle inventory). Life Cycle Inventory analysis (LCI) is defined as a phase of Life Cycle Assessment (LCA) involving the compilation and quantification of inputs and outputs for a given product system throughout its life cycle (ISO 14040). The concept of LCI has been adopted for cleaner production as early as the 1960s, and has had broad industrial and academic application in the last decades [5].

\section{Methodology}

Life cycle inventory (LCI) is the most work intensive and time consuming compared to other phases in an LCA, mainly because of data collection. The data collection can be less time consuming if good databases are available and if the industry is willing to help. Many LCA databases exist and can normally be bought together with LCA software. Data on transport, extraction of raw materials, processing of materials, production of usually used products such as plastic and cardboard, and disposal can normally be found in an LCA database. Data from databases can be used for processes that are not product specific, such as general data on the production of electricity, coal or packaging. For product-specific data, site-specific data are required. The data should include all inputs and outputs from the processes. Inputs are energy (renewable and non-renewable), water, raw materials, etc. Outputs are the products and co-products, and emission such as $\mathrm{CO}_{2}, \mathrm{CH}_{4}, \mathrm{SO}_{2}, \mathrm{NO}_{\mathrm{x}}$ and $\mathrm{CO}$ to air.

The ISO 14041 guidelines suggest energy and material flows that do not constitute a significant portion of intermediate or final products need not be included in the life cycle inventory if they have a negligible environmental impact. Thus, the energy, materials, and emissions associated with RTI building are not included in this life cycle inventory. The major efforts for inventory data in this study were done by generating the required data for new case. In this regard, all the input and output materials and energy for each unit were calculated based on the quantity of the products. Therefore, the primary data in this study was obtained by measuring input and output of the tempeh production using some equipment. 
Process flow diagrams show how processes of a product system are interconnected through commodity flows. In process flow diagrams, boxes generally represent processes and arrows the commodity flows (Fig.5). Each process is represented as a ratio between a number of inputs and outputs [6].

\section{Results and Discussion}

Gambung Tea Factory Located in Bandung regency, $176 \mathrm{~km}$ from Jakarta which was managed by Research Center for Tea and quinine. Flow diagram of Gambung Green Tea shown in the following figure.

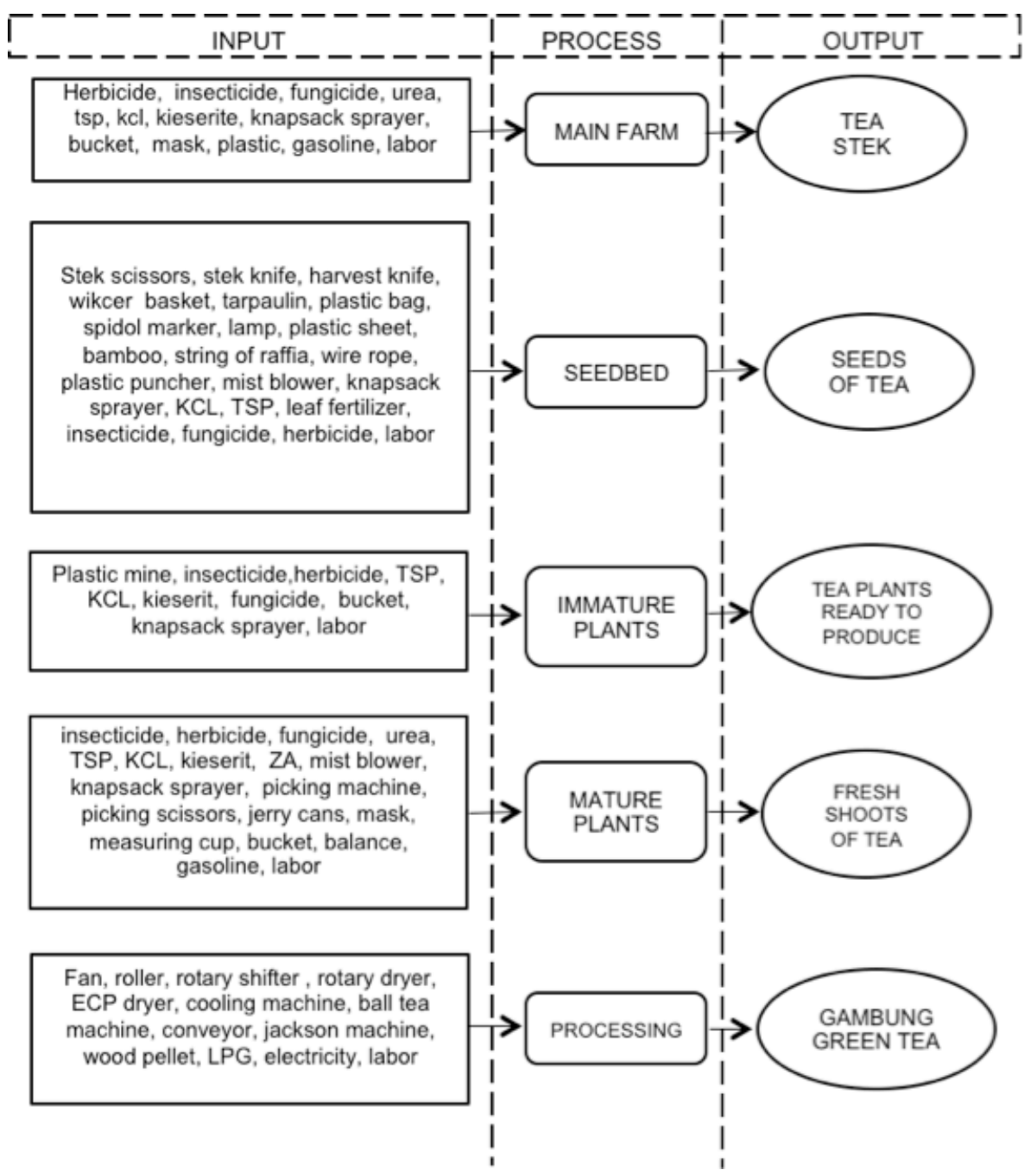

Fig. 1. Flow diagram Gambung green tea; input, process, output 
Life cycle inventory boundary for this study was gate to gate, only in the processing tea. The processing of green tea can be described as follows; Fresh shoots from the picking are brought to the tea processing factory. The tea is then spread while being aerated with the help of an electric fan to reduce the water content. Furthermore, with the help of the tea conveyor belt, the winding process is carried out using a double cylinder rotary panner tool which is driven using an electric motor. In this process heat is supplied from the burning of wood pellets. The winding process is run at a temperature of less than $100 \mathrm{C}$ for a 3 minute process, the water content of this process is $60 \%$.

The next process of tea leaves is cooled then a rolling process using a roller is run at room temperature for 20 minutes at a speed of $60 \mathrm{rpm}$. The tea leaves are then dried using an ECP device which is driven by an electric motor and LPG heater. The process temperature is $130^{\circ} \mathrm{C}$ for 25 minutes, the yield of tea leaves is about $35 \%$ water. Then with the help of tea leaf conveyor belts brought to the sorting process using a rotary shifter with an electric motor drive.

After sorting, the following process of tea leaves is the second heating using electricity and LPG heaters. The heating process is carried out for 2 hours using a rotary dryer and 6 hours using ball tea. The moisture content of the tea leaves results from a second drying process of $4 \%$. Bulk tea leaf products are then carried out by bulk packaging using $40 \mathrm{~kg}$ size sacks per sack. Process flow diagram as shown in the following figure. For the information, blue letter indicate for energy, red letter indacete for machine or electricity.
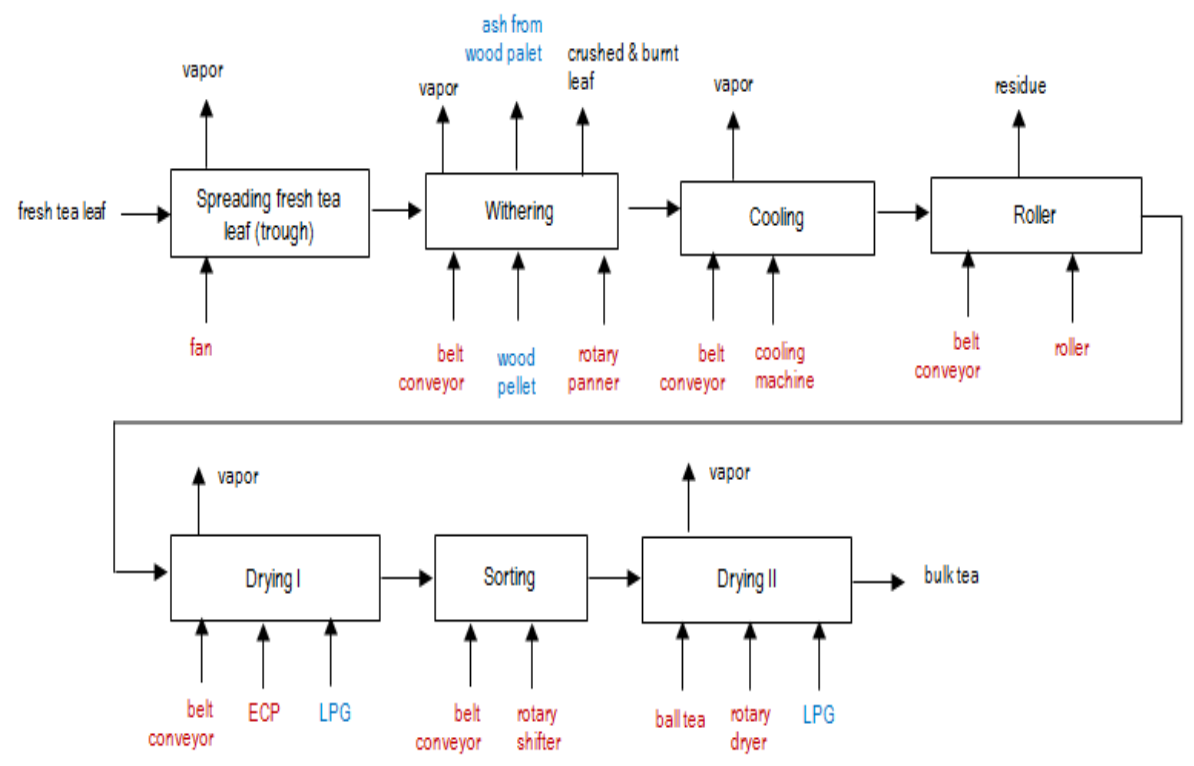

Fig. 2. Green tea production processes 
Based on direct interview and secondary data collected to the Gambung-West Java green tea industry, the mass balance of the tea production process was summarized as follows.

Table 1. Mass balance green tea production

\begin{tabular}{|l|l|l|l|r|}
\hline \multicolumn{1}{|c|}{ Processes } & \multicolumn{2}{c|}{ Input (kg) } & \multicolumn{2}{c|}{ Output (kg) } \\
\hline $\begin{array}{l}\text { 1. Spreading fresh tea } \\
\text { leaf }\end{array}$ & Fresh tea leaf & 15,000 & Lead ready to wither & 14,250 \\
\hline & & & vapor & 750 \\
\hline 2. Withering & $\begin{array}{l}\text { Lead ready to } \\
\text { wither }\end{array}$ & 14,250 & Withered leaf & 10,370 \\
\hline & & & vapor & 3,750 \\
\hline & & & Crushed \& burnt leaf & 130 \\
\hline 3. cooling & Withered leaf & 10,370 & Leaf ready to roll & 8,815 \\
\hline & & & vapor & 1,555 \\
\hline 4. roller & Leaf ready to roll & 8,815 & Rolled leaf & 8,750 \\
\hline & & & Residue (fluff of leaf) & 65 \\
\hline 5. drying I & Rolled leaf & 8,750 & Dried leaf & 5,250 \\
\hline & & & vapor & 3,500 \\
\hline 6. Sorting & Dried leaf & 5,250 & Tea leaf I & 2,625 \\
\hline & & & Tea leaf II & 2,625 \\
\hline 7. drying II & Tea leaf I dan II & 5,250 & Bulk tea & 3,218 \\
\hline & & & vapor & 2,032 \\
\hline
\end{tabular}

Producing 3.2 tons of bulk tea requires 15 tons of fresh shoots and release 11 tons of steam, 0.4 tons of residue and 0.3 tons of crushed tea leaves. The process also requires 31 unit of $50 \mathrm{~kg}$ LPG cylinders.

\section{Conclusion}

In this study, inventory analysis has been performed toward green production system, using gate to gate approach. Tea from the plantation entering the production line and processed, resulting bulk of tea. The result of such inventory analysis indicates that to produce 3.2 ton of bulk green tea, needs 15 ton of fresh tea leaf, 31 tubes LPG of $50 \mathrm{~kg}$ and 2.7 ton wood pellet are needed. This process also produces $54 \mathrm{~kg}$ waste of ash wood pellet, 0.3 ton crushed-burnt leaf, 0.4 ton residue, and 11 ton vapor released.

The result of this study can be utilzed to conduct further analysis using life cycle assessment approach, to estimate the potential environmental impact and propose improvement recommendation. 


\section{References}

1. Fava Neves M., Trombin V.G., Lopes F.F., Kalaki R., Milan P., 2011, The Orange Juce Business: A Brazilian Perspective, Wageningen Academic Publishers

2. FAO (2014). FAOSTAT [Online]. (Accessed November 2018), http://www.FAO.org

3. ISO. Environmental management, life cycle assessment requirements and guidelines (ISO 14044). (International Organization for Standardization, Geneva, 2006)

4. J.L. Taulo, A.B. Sebitosi, Material and energy flow analysis of the Malawian tea industry, Renewable and Sust. Energy Rev., 56, 1337-1350 (2016)

5. Vigon, B. W., Tolle, D. A., Cornaby, B. W., Latham, H. C., Harrison, C. L., Boguski, T. L., Hunt, R. G., \& Sellers, J. D. (1993). Life cycle assessment: Inventory guidelines and principles, EPA/600/R-92/245. Washington, DC: USEPA

6. S. Suh, G. Huppes. Methods for Life Cycle Inventory of a Product. J. of Clean. Production, 13, 687-697 (2005) 